\title{
BMJ Open A cross-sectional survey of essential surgical capacity in Somalia
}

\author{
Natalie Elkheir, ${ }^{1}$ Akshay Sharma, ${ }^{2}$ Meena Cherian, ${ }^{3}$ Omar Abdelrahman Saleh, ${ }^{4}$ \\ Marthe Everard, ${ }^{4}$ Ghulam Rabani Popal, ${ }^{4}$ Abdi Awad Ibrahim ${ }^{5}$
}

To cite: Elkheir N, Sharma A, Cherian $\mathrm{M}$, et al. A crosssectional survey of essential surgical capacity in Somalia. BMJ Open 2014:4:e004360. doi:10.1136/bmjopen-2013004360

- Prepublication history for this paper is available online. To view these files please visit the journal online (http://dx.doi.org/10.1136/ bmjopen-2013-004360).

Received 29 October 2013 Revised 29 January 2014 Accepted 31 January 2014

\section{CrossMark}

\author{
${ }^{1}$ St George's Hospital, \\ London, UK \\ ${ }^{2}$ Harvard College, Harvard \\ University, Cambridge, \\ Massachusetts, USA \\ ${ }^{3}$ Emergency \& Essential \\ Surgical Care Programme, \\ Health Systems and \\ Innovation, World Health \\ Organization-HQ, Geneva, \\ Switzerland \\ ${ }^{4}$ World Health Organization \\ Somalia, Nairobi, Kenya \\ ${ }^{5}$ Ministry of Health Somalia, \\ Mogadishu, Somalia
}

Correspondence to Akshay Sharma; akshay1227@gmail.com

\section{ABSTRACT}

Objective: To assess life-saving and disabilitypreventing surgical services (including emergency, trauma, obstetrics, anaesthesia) of health facilities in Somalia and to assist in the planning of strategies for strengthening surgical care systems.

Design: Cross-sectional survey.

Setting: Health facilities in all 3 administrative zones of Somalia; northwest Somalia (NWS), known as Somaliland; northeast Somalia (NES), known as Puntland; and south/central Somalia (SCS).

Participants: 14 health facilities.

Measures: The WHO Tool for Situational Analysis to Assess Emergency and Essential Surgical Care was employed to capture a health facility's capacity to deliver surgical and anaesthesia services by investigating four categories of data: infrastructure, human resources, interventions available and equipment.

Results: The 14 facilities surveyed in Somalia represent 10 of the 18 districts throughout the country. The facilities serve an average patient population of 331250 people, and 12 of the 14 identify as hospitals. While major surgical procedures were provided at many facilities (caesarean section, laparotomy, appendicectomy, etc), only $22 \%$ had fully available oxygen access, $50 \%$ fully available electricity and less than $30 \%$ had any management guidelines for emergency and surgical care. Furthermore, only $36 \%$ were able to provide general anaesthesia inhalation due to lack of skills, supplies and equipment. Basic supplies for airway management and the prevention of infection transmission were severely lacking in most facilities. Conclusions: According to the results of the WHO Tool for Situational Analysis to Assess Emergency and Essential Surgical Care survey, there exist significant gaps in the capacity of emergency and essential surgical services in Somalia including inadequacies in essential equipment, service provision and infrastructure. The information provided by the WHO tool can serve as a basis for evidence-based decisions on country-level policy regarding the allocation of resources and provision of emergency and essential surgical services.

\section{INTRODUCTION}

Conditions that can be treated with surgery account for $11 \%$ of the world's disabilityadjusted life years. ${ }^{1}$ Despite recent data

\section{Strengths and limitations of this study}

- Provides insight into the surgical capacity of Somalia.

- Identifies significant gaps and areas for improvement towards evidence-based planning to improve surgical infrastructure, skills training and equipment and supplies.

- Does not capture data from every first-referral health facility of the country.

- In some cases, measures captured are estimates.

estimating the global volume of surgery at 234 million surgical procedures annually and significant disparities between procedures performed in high-income and low-income countries, global public health initiatives have traditionally neglected the necessity for the provision of surgical services. ${ }^{2}$ Poor access to surgical services, particularly at rural facilities, results in excess morbidity and mortality from a broad range of treatable surgical conditions including injuries, complications of pregnancy, sequelae of infectious diseases, acute abdominal conditions and congenital abnormalities. Improving access to surgical services in lowincome countries requires addressing gaps in infrastructure, training and skills of personnel, appropriate equipment and medications.

\section{Background}

Somalia's 21 years of war, armed conflict and insecurity have had a devastating effect on the health sector. The current situation is at its worst since the beginning of the civil war in 1991, with unprecedented levels of child malnutrition and internal displacement, as well as conflict and insecurity rife in parts of the country. ${ }^{3}$ Continuing conflict has left $90 \%$ of health infrastructure looted, damaged or destroyed. ${ }^{4}$ The low health workforce ratios before the war have depreciated through high levels of healthcare worker emigration, leaving an estimated 3 physicians per 100000 population (total 253 physicians), 11 nurses per 
100000 population (861 nurses) and 2 midwives per 100000 population (116 midwives) serving the whole country. ${ }^{5}$

Rates of death and disability from treatable surgical conditions continue to be unacceptably high. Somalia's maternal mortality rate is estimated to be 1044 per 100000 live-births, one of the highest in the region. ${ }^{6}$ This corresponds to a lifetime risk of one maternal death for every 10 women. The leading causes of maternal death (antepartum and postpartum haemorrhage, obstructed labour and eclampsia) can all be addressed with appropriate emergency obstetric care, which often require surgical and anaesthetic interventions. Trauma, as a consequence of road traffic accidents, armed fighting and landmine explosions, is also common. In 2010 and 2011, WHO reported more than 7500 war-wounded civilians who were admitted to the three main hospitals in Mogadishu, one in five being children and one in three women (WHO. Emergency and Essential Surgical Care. 2013. http://www.who.int/surgery/en/).

The health sector faces overwhelming challenges in a country where two decades of lawlessness have resulted in the collapse of central government and three almost autonomously ruled zones: northwest Somalia (NWS), known as Somaliland; northeast Somalia (NES), known as Puntland; and south/central Somalia (SCS). Somalia's public health system is tiered, comprising regional referral hospitals, district hospitals, maternal and child health centres and health posts. However, hospitals and health facilities are limited in number, inadequately distributed, operate using vastly different standards and often cannot provide a minimum package of primary healthcare (PHC) services. As funders and public health experts adopt the expansion of primary healthcare services, the inclusion of surgical services at the first-referral level is critical. The purpose of this survey was to collect knowledge gained from comprehensive quantitative assessments of surgical capacity in Somalia in order to assist in planning strategies for universal access to life-saving and disability-preventing surgical services (WHO. Emergency and Essential Surgical Care. 2013. http://www.who.int/surgery/en/).

Similar studies using the WHO Situational Analysis tool have been conducted in Tanzania, ${ }^{7}$ Solomon Islands, ${ }^{8}$ Gambia, ${ }^{9}$ Liberia, ${ }^{10}$ Ghana, ${ }^{11}$ Afghanistan, ${ }^{12}$ Sri Lanka, ${ }^{13}$ Sierra Leone ${ }^{14}$ and Mongolia. ${ }^{15}$

\section{OBJECTIVE}

The objective of this study was to assess life-saving and disability-preventing surgical services (including emergency, trauma, obstetrics, anaesthesia) of health facilities in Somalia and to assist in the planning of strategies for strengthening surgical care systems.

The aim of the study was also to assess the current capacity for essential anaesthesia and surgical services in Somalia with the purpose of providing a benchmark for critical areas needing improvement.

\section{METHODS}

The WHO Tool for Situational Analysis to Assess Emergency and Essential Surgical Care (EESC) was employed to capture a health facility's capacity to perform basic surgical (including obstetrics and trauma) and anaesthesia interventions by investigating four categories of data: infrastructure, human resources, interventions provided and equipment availability. The tool queries the availability of eight types of care providers, 35 surgical interventions and 67 items of equipment. ${ }^{7}$ The answer 'available' was defined as 'fully available for all patients all of the time', while 'sometimes' was defined as 'available with frequent shortages or difficulties' (WHO EESC Situational Analysis Tool, 2012, http://www.who.int/ surgery/publications/WHO_EESC_SituationAnalysisTool. pdf).

Facilities were also asked the size of the 'population served', intending to quantify the population living in the catchment area. This value represents the number of residents who might use the facility as their firstreferral health facility, not the number of patients seen.

The WHO Tool for Situational Analysis to Assess EESC was distributed by the Ministry of Health and WHO Somalia to 20 first-referral level health facilities around the country and was completed at 14 health facilities representing 10 of the 18 regions of Somalia and all three administrative zones. The survey was extended to regional medical officers and facility administrators. Participation in the survey and reporting to the WHO was voluntary. The physical surveys were then obtained either by post directly to the WHO Somalia office (Nairobi, Kenya) or by site visits from the Somalia Ministry of Health $(\mathrm{MoH})$, the WHO country office and members of the Global Initiative for EESC (GIEESC) between September 2011 and April 2012.

Despite efforts to standardise the reporting and collection of much of the data by site visits performed by agents affiliated to the authors, it must be noted that an inherent reporting bias may be present in the data, given that survey data were compiled by different agents at each site. Furthermore, in a limited number of cases, facilities did not respond to individual questions. Blank answers were considered as neither a positive or negative answer, but simply deemed as unreported.

The collected data were then entered into and analysed from WHO Global DataCol Database for EESC.

\section{RESULTS}

Data were gathered from 14 health facilities in 10 regions (of 18) across Somalia, as featured in figure 1 and table 1 . The six facilities that received the survey but did not return information are also listed in table 1 . Non-reporting can be attributed to lack of consistent operation, inability to gather data, and pervasive political instability and high-security risk throughout the country, making the transmission of this data difficult and costly. 


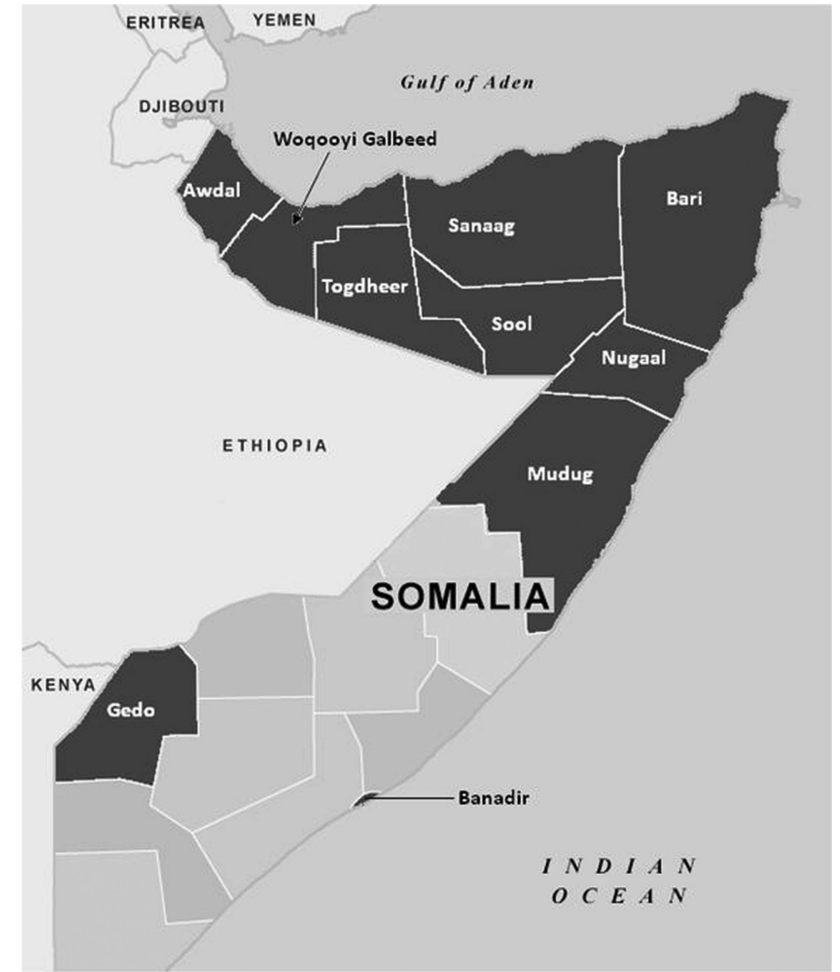

Figure 1 Participating regions of Somalia.

\section{Health facility characteristics}

Of the 14 facilities that responded to the survey, 5 were provincial hospitals, 5 were private/mission/NGO hospitals, 3 were general hospitals and 1 was a health centre. Each facility reported having at least 1 operating theatre, with a maximum of 11-20 operating theatres. The populations served by each facility ranged from 100000 to 1000000 people, with the average population of the reporting facilities at 331250 people.

\section{Infrastructure}

The emergency and surgical infrastructure of the 14 reporting facilities were largely inadequate, with only $22 \%$ of the health facilities having oxygen cylinder supplies consistently available. $28 \%$ of the facilities never or only sometimes had access to running water and only $50 \%$ had a consistently available electricity source. Only $50 \%$ of the facilities had fully available access to running water and electricity. Access to a functional anaesthesia machine was only present in $2(15 \%)$ facilities, one of those facilities being a local health centre. Only three facilities reported access to a functioning pulse-oximeter.

Fifty per cent of the facilities had permanent areas designated for emergency care and only $38 \%$ of the facilities had the same for postoperative care.

A minority of facilities had formal management guidelines for emergency care $(3 / 14=21 \%)$, surgery $(5 / 14=36 \%)$, anaesthesia $(4 / 14=29 \%)$ or pain relief $(1 / 14=7 \%)$.

Table 2 depicts the key infrastructural elements available in the health facilities assessed.

\section{Human resources}

More data are needed to comment on human resources within healthcare in Somalia. In this section of the survey, blank answers to staffing questions impeded our ability to comment on the state of the workforce completely. We did, however, summarise the results of the survey questions to which all or a majority of facilities supplied data.

The 14 facilities together reported a total of 137 healthcare providers. Only $15(11 \%)$ individuals were identified as full-time trained surgical specialists, located only at 9 of 14 of the facilities. A total of $14(11 \%)$ were identified as obstetricians, and only 4 (3\%) individuals were identified as qualified anaesthesiologists and were located in only 3 of the 14 facilities, with $27(20 \%)$ unlicensed medical staff (nurses, medical assistants, etc) providing anaesthetic services.

\section{Interventions}

Of the 35 interventions queried, only abscess incision and drainage were offered at all 14 facilities. Acute burn management, wound debridement, hydrocoele treatment and male circumcision were widely provided by the surveyed facilities, being offered at $85-86 \%$ of all facilities. Caesarean section was offered at $93 \%$ of all facilities.

Provision of anaesthesia services was severely lacking, however, with only $36 \%$ of facilities able to perform general anaesthesia inhalational procedures. Of the eight facilities that answered why they could not provide this service, one (Doolow Health Center) attributed it to lack of skill and four (Borama General Hospital, Doolow Health Center, Erigavo Regional Hospital, Burao Regional Hospital) to lack of supplies or drugs. One facility (Gardo General Hospital) attributed it to lack of skill and lack of equipment.

The ability of each health facility to provide basic surgical and anaesthesia procedures was assessed (tables 3 and 4).

\section{Emergency equipment and supplies for resuscitation}

Basic equipment access was also lacking. No facility had access to all basic and essential surgical equipment listed by the tool. Only one hospital always had adult resuscitator bag valves and masks available, and only 2 of 14 facilities reported the same for paediatric bag valves and masks. Sixty-four per cent of the facilities had access to oxygen only sometimes or never, and less than $30 \%$ had oropharyngeal airways always available for adults and children. Thirty-nine per cent of institutions were without an examination table.

Basic equipment such as suction catheters, intravenous cannulas and Foley catheters were consistently available in less than $30 \%$ of all facilities.

Fifty-seven per cent of the facilities did not have sterile gloves consistently available, and $64 \%$ reported the same for examination gloves. Only $64 \%$ of the reporting 
Table 1 Surveyed health facilities $(\mathrm{N}=14)$

\begin{tabular}{|c|c|c|c|c|}
\hline Type of facility (self-identified) & Name of facility & Region & $\begin{array}{l}\text { Number } \\
\text { of beds }\end{array}$ & $\begin{array}{l}\text { Operating } \\
\text { theatres }\end{array}$ \\
\hline \multirow[t]{3}{*}{ General hospital } & Garowe Hospital & Nugaal & $51-80$ & $11-20$ \\
\hline & Gardo General Hospital & Bari & $21-50$ & 1 \\
\hline & Hergeisa Group Hospital & $\begin{array}{l}\text { Woqooyi } \\
\text { Galbeed }\end{array}$ & $301-400$ & $5-10$ \\
\hline \multirow[t]{5}{*}{ Provincial hospital } & Borama General Hospital & Awdal & $201-300$ & 1 \\
\hline & Burao Regional Hospital & Togdeer & $201-300$ & 1 \\
\hline & Berbera Referral Hospital & $\begin{array}{l}\text { Woqooyi } \\
\text { Galbeed }\end{array}$ & $101-200$ & 2 \\
\hline & Erigavo Regional Hospital & Sanaag & $81-100$ & 1 \\
\hline & Sool Regional Hospital & Sool & $81-100$ & 1 \\
\hline Health centre & Doolow Health Centre & Gedo & $5-10$ & 1 \\
\hline \multirow[t]{5}{*}{ Private/NGO/mission hospital } & Galkayo Medical Centre & Mudug & $51-80$ & $3-4$ \\
\hline & Galkayo Specialist Hospital & Mudug & $3-4$ & 1 \\
\hline & Medina Hospital & Banadir & $201-300$ & $5-10$ \\
\hline & Maani Hospital & Banadir & $21-50$ & 1 \\
\hline & Manhal Specialty Hospital & $\begin{array}{l}\text { Woqooyi } \\
\text { Galbeed }\end{array}$ & $51-80$ & $5-10$ \\
\hline \multirow[t]{6}{*}{$\begin{array}{l}\text { Facilities not responding to } \\
\text { survey }\end{array}$} & Shikh Hospital & $\begin{array}{l}\text { Woqooyi } \\
\text { Galbeed }\end{array}$ & NA & NA \\
\hline & Puntland Regional Hospital & Bossaso & NA & NA \\
\hline & General Medical Service Hospital & Mudug & NA & NA \\
\hline & Wajed Hospital & Bakool & NA & NA \\
\hline & Dinsor Hospital & Bakool & NA & NA \\
\hline & Sama Hospital & Bay & NA & NA \\
\hline
\end{tabular}

institutions had a steriliser available all the time. Seventy-one per cent did not have face masks available, and $86 \%$ were without consistent availability of eye protection. Availability of soap and wash basins was reported in less than two-thirds of the 14 facilities.

The availability of emergency equipment and supplies for resuscitation was assessed in each of the health facilities (depicted in tables 5-7).

\section{LIMITATIONS}

There are several limitations to this survey. It provides only a brief overview of the capacity for surgical care and cannot be used for detailed programme planning. Although not every first-referral health facility in Somalia was surveyed, the majority identified by the $\mathrm{MoH}$ and WHO Somalia did reply and this allows a credible insight into the surgical capacity of the country.

Table 2 Availability of infrastructure and health resources in Somalia, $2012(\mathrm{~N}=14)$

\begin{tabular}{lccc}
\hline & Always & Sometimes & Not available \\
\hline Oxygen cylinder & 3 & 1 & 10 \\
Running water & 10 & 2 & 2 \\
Electricity source & 7 & 5 & 2 \\
Operational power generator & 2 & 2 & 9 \\
Blood bank & 5 & 3 & 6 \\
Haemoglobin and urine testing & 12 & 2 & 0 \\
X-ray machine & 8 & 4 & 2 \\
Medical records & 10 & 3 & 1 \\
Pulse oximeter & 3 & 0 & 8 \\
Area designated for emergency care & 5 & 1 & 7 \\
Area designated for postoperative care & 5 & 1 & 1 \\
Management guidelines for emergency care & 3 & 1 & 9 \\
Management guidelines for surgery & 5 & 0 & 9 \\
Management guidelines for anaesthesia & 4 & 1 & 10 \\
Management guidelines for pain relief & 1 & 3 & 2 \\
Functioning anaesthesia machine & 7 & 5 & \\
\hline Number of facilies where element always, sometimer & & \\
\end{tabular}

Number of facilities where element is always, sometimes or never available. Italicised items designate those that are specific to quality surgical care delivery $(\mathrm{N}=14)$. 
Table 3 Availability of surgical (including obstetrics and trauma) interventions

\begin{tabular}{|c|c|c|}
\hline General surgery and trauma & \multicolumn{2}{|c|}{ Available } \\
\hline $\begin{array}{l}\text { Resuscitation (airway, haemorrhage, peripheral percutaneous intravenous access, peripheral venous cut } \\
\text { down) }\end{array}$ & \multicolumn{2}{|l|}{11} \\
\hline Cricothyroidotomy/tracheostomy & \multicolumn{2}{|l|}{10} \\
\hline Chest tube insertion & \multicolumn{2}{|l|}{9} \\
\hline Removal of foreign body (throat/ear/eye/nose) & \multicolumn{2}{|l|}{11} \\
\hline Acute burn management & \multicolumn{2}{|l|}{12} \\
\hline Incision and drainage of abscess & \multicolumn{2}{|l|}{14} \\
\hline Suturing (for wounds, episiotomy, cervical and vaginal lacerations) & \multicolumn{2}{|l|}{13} \\
\hline Wound debridement & \multicolumn{2}{|l|}{11} \\
\hline Caesarean section & \multicolumn{2}{|l|}{13} \\
\hline Dilation and curettage (gynaecology/obstetrics) & \multicolumn{2}{|l|}{12} \\
\hline Obstetric fistula repair & \multicolumn{2}{|l|}{7} \\
\hline Appendicectomy & \multicolumn{2}{|l|}{11} \\
\hline Hernia repair (strangulated, elective) & \multicolumn{2}{|l|}{10} \\
\hline Hydrocoele & \multicolumn{2}{|l|}{12} \\
\hline Cystostomy & \multicolumn{2}{|l|}{9} \\
\hline Urethral stricture dilation & \multicolumn{2}{|l|}{11} \\
\hline Laparotomy (uterine rupture, ectopic pregnancy, acute abdomen, intestinal obstruction, perforation, injuries) & \multicolumn{2}{|l|}{12} \\
\hline Male circumcision & \multicolumn{2}{|l|}{12} \\
\hline Congenital hernia repair & \multicolumn{2}{|l|}{9} \\
\hline Neonatal surgery (abdominal wall defect, colostomy imperforate anus, intussusceptions) & \multicolumn{2}{|l|}{5} \\
\hline Cleft lip repair & \multicolumn{2}{|l|}{10} \\
\hline Clubfoot repair & \multicolumn{2}{|l|}{9} \\
\hline Contracture release/ skin grafting & \multicolumn{2}{|l|}{10} \\
\hline \multirow[t]{2}{*}{ Fracture treatment } & Closed & Open \\
\hline & \multicolumn{2}{|c|}{$10 \quad 8$} \\
\hline Joint dislocation treatment & \multicolumn{2}{|l|}{9} \\
\hline Drainage of osteomyelitis/septic arthritis & \multicolumn{2}{|l|}{9} \\
\hline Amputation & \multicolumn{2}{|l|}{11} \\
\hline Biopsy (lymph node, mass, other) & \multicolumn{2}{|l|}{8} \\
\hline Tubal ligation/vasectomy & \multicolumn{2}{|l|}{9} \\
\hline Cataract surgery & \multicolumn{2}{|l|}{4} \\
\hline
\end{tabular}

Number of facilities at which the procedure is available $(\mathrm{N}=14)$.

Some of the data was taken after the WHO IMEESC toolkit was implemented in the country, and results should be qualified by the possibility of interpretation constraints of the survey.

\section{DISCUSSION}

Surgically treatable diseases are among the top 15 causes of disability, ${ }^{16}$ and conservative estimates show that $11 \%$ of the world's disability-adjusted life years (DALYs) stem from surgically treatable conditions. ${ }^{1}$ In 2004, South East Asia and Africa accounted for $54 \%$ of the global burden, ${ }^{17}$ and since then the burden of surgical disease is thought to be increasing. ${ }^{16}$

More than two billion people globally are without access to surgical care. ${ }^{18}$ Of the 243 million surgical procedures performed globally each year, $34.8 \%$ of the world's population living in low-income countries only has access to 8.1 million $(3.5 \%)$ of such procedures. ${ }^{2}$ As a result, rates of maternal mortality are high, minor surgical pathologies become lethal and treatable trauma progresses to death.
Despite the great, unmet need and inclusion in policylevel dialogue on primary healthcare, the delivery of emergency surgical care has long been sidelined in global financing and policy debates, largely due to perceived complexity and cost. Human resources, metrics and science focused on global surgery, and sustained financing mechanisms for surgical infrastructure lag behind other public health priorities, despite the growing need for access to surgical care. ${ }^{19}$

Enormous shortfalls in infrastructure, supplies and procedures undertaken are common at districtlevel health facilities in LMICs. $^{20}$ Every $\$ 1$ spent

Table 4 Availability of anaesthesia interventions

\begin{tabular}{lr}
\hline Anaesthesia & 6 \\
\hline Regional anaesthesia blocks & 13 \\
Spinal anaesthesia & 13 \\
Ketamine intravenous anaesthesia & 5 \\
General anaesthesia inhalational &
\end{tabular}


Table 5 Availability of capital outlays for resuscitation

\begin{tabular}{|c|c|c|c|}
\hline Capital outlays & Always & Sometimes & Never \\
\hline \multicolumn{4}{|l|}{ Resuscitator bag valve and mask } \\
\hline Adult & 1 & 7 & 6 \\
\hline Paediatric & 2 & 5 & 7 \\
\hline Oxygen & 5 & 4 & 5 \\
\hline Stethoscope & 9 & 3 & 0 \\
\hline Batteries for flash light & 8 & 2 & 4 \\
\hline Suction pump & 11 & 3 & 0 \\
\hline Blood pressure monitoring equipment & 10 & 3 & 1 \\
\hline Thermometer & 10 & 3 & 1 \\
\hline Scalpel handle with blade & 9 & 4 & 1 \\
\hline Retractor & 7 & 6 & 0 \\
\hline Scissors straight $12 \mathrm{~cm}$ & 8 & 5 & 1 \\
\hline Scissors blunt $14 \mathrm{~cm}$ & 7 & 6 & 0 \\
\hline \multicolumn{4}{|l|}{ Oropharyngeal airway } \\
\hline Adult & 4 & 6 & 4 \\
\hline Paediatric & 4 & 5 & 5 \\
\hline Forceps Kocher no teeth & 5 & 7 & 1 \\
\hline Forceps, artery & 8 & 6 & 0 \\
\hline Kidney dishes stainless steel & 6 & 6 & 1 \\
\hline Capped bottle, alcohol-based solutions & 2 & 5 & 3 \\
\hline Gloves (sterile) & 6 & 7 & 1 \\
\hline Gloves (examination) & 5 & 8 & 1 \\
\hline Needle holder & 9 & 5 & 0 \\
\hline Steriliser & 9 & 5 & 0 \\
\hline Nail brush, scrubbing surgeon's & 7 & 5 & 1 \\
\hline Vaginal speculum & 9 & 2 & 3 \\
\hline Bucket, plastic & 4 & 4 & 4 \\
\hline Drum for sterile compresses, bandages, dressings & 8 & 4 & 1 \\
\hline Examination table & 8 & 4 & 1 \\
\hline
\end{tabular}

strengthening local surgical capacity generates $\$ 10$ through improved health and increased productivity. ${ }^{21}$ In 2008, the Copenhagen Consensus Center's research identified strengthening surgical capacity, particularly at the district hospital level, as a highly cost-efficient solution to global diseases. Notably, strengthening local surgical capacity is an approach that would provide a high degree of financial protection to populations and address the DALYs in a cost-effective manner. ${ }^{1}$ In fact, the benefit-cost ratio for expansion of surgical capacity at district hospitals was found to be $10: 1 .^{22}$ Furthermore, due to the implementation of 'vertical' programmes in public health (ie, child health, maternal health, cancer and trauma), in which most programmes contain some surgical component, strengthening surgical services may improve the health system overall. ${ }^{23}$

This study provides an overview of the capacity for surgical care representing health facilities in all three administrative zones of Somalia, including 10 of the 18 regions and demonstrates the significant gaps in infrastructure, life-saving and disability-preventing surgical interventions and essential equipment. Of the 14 reporting health facilities, 12 identified as full hospitals, serving an average patient population of over 300000 people, further indicating the need for surgical care system strengthening.

Of the 35 basic surgical and anaesthesia interventions queried, most hospitals were unable to provide all of the basic surgical services. Major essential procedures such as caesarean section, appendicectomy, elective hernia and hydrocoele repair and laparotomy were offered at a majority of hospitals, but this conflicted directly with the continuous availability of basic and necessary supplies and infrastructures. Only three facilities had consistent access to oxygen cylinders, and even less reported access to tubing, valves and masks.

Necessary procedures including resuscitation and airway management were offered at a majority $(79 \%)$ of the facilities. Facilities that weren't able to provide resuscitation, however, all reported provision of major surgical procedures. Such surgical procedures require provision and knowledge of resuscitation in order to be carried out safely. The facilities in question could not be contacted for confirmation.

Many facilities lacked access to key elements such as provisional oxygen equipment, oropharyngeal airways and intravenous cannulas. Only two facilities reported access to functional anaesthesia machines, and few facilities noted the ability to provide general anaesthesia 
Table 6 Availability of renewable supplies for resuscitation

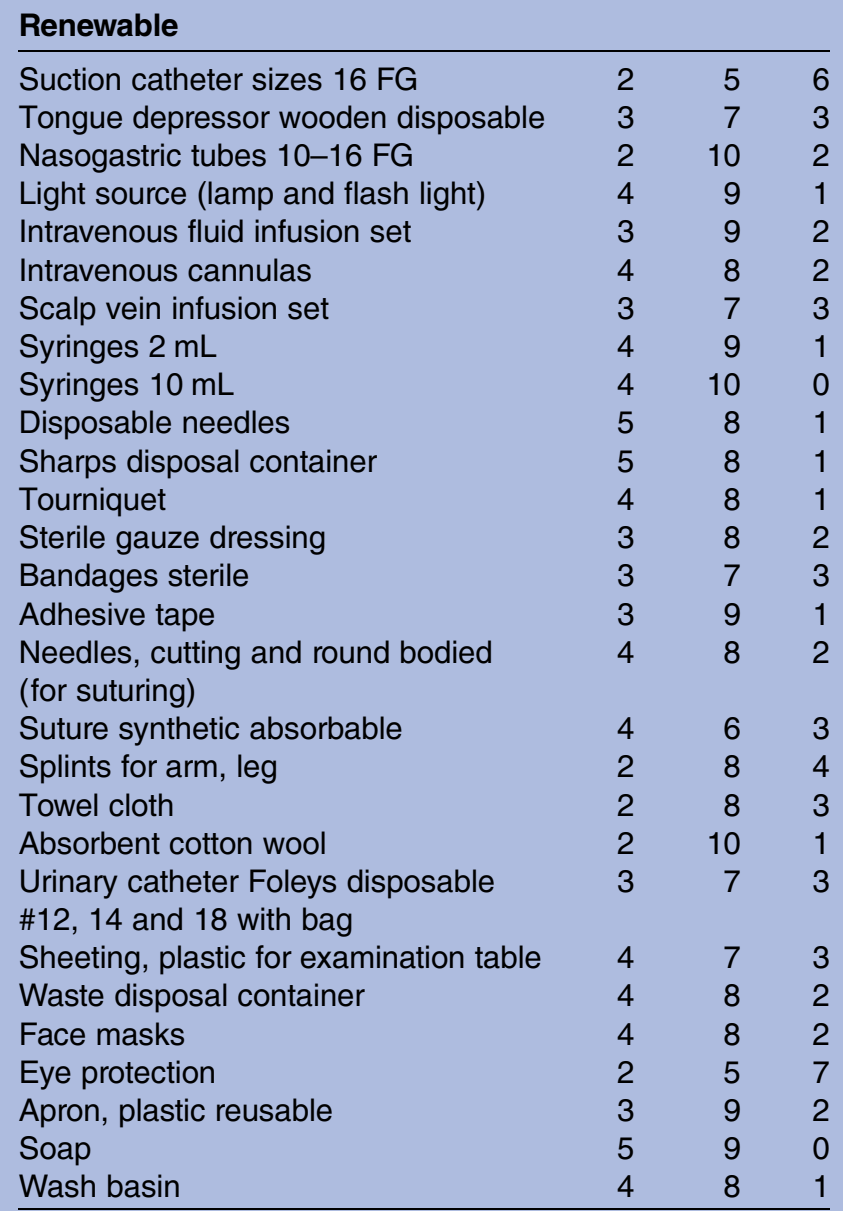

Number of facilities where element is always, sometimes or never available ( $\mathrm{N}=14)$.

inhalation. Oxygen and anaesthesia are essential medicines, (WHO Model List of Essential Medicines, WHO, 2013. http://www.who.int/medicines/publications/ essentialmedicines/18th_EML_Final_web_8Jul13.pdf) and the existing deficit limits the safety and efficacy of life-

\begin{tabular}{|c|c|c|c|}
\hline \multicolumn{4}{|l|}{ Supplementary equipment } \\
\hline \multicolumn{4}{|l|}{ Magills forceps } \\
\hline Adult & 3 & 2 & 9 \\
\hline Paediatric & 1 & 2 & 10 \\
\hline Endotracheal tubes & 1 & 2 & 10 \\
\hline Intravenous infusor bags & 1 & 2 & 10 \\
\hline Chest tubes insertion equipment & 1 & 3 & 9 \\
\hline \multicolumn{4}{|l|}{ Laryngoscope } \\
\hline Adult & 3 & 3 & 7 \\
\hline Paediatric & 1 & 3 & 9 \\
\hline Cricothyroidotomy set & 1 & 1 & 11 \\
\hline
\end{tabular}

Number of facilities where element is always, sometimes or never available $(\mathrm{N}=14)$. saving surgeries in Somalia. It can also result in significant complications or patient suffering when these medicines are not available. ${ }^{24}$

A surprisingly low number of facilities reported having access to equipment necessary for prevention of HIV transmission and other infection control. Less than half of the facilities reported access to sterile gloves, waste disposal containers, face masks, eye masks, aprons and even soap, all key components in the reduction of HIV transmission (WHO Prevention of Transmission of HIV, 2007, http://www.who.int/surgery/publications/ HIVprevention.pdf)

A majority of the facilities lacked any formal guidelines for the management of emergency care, surgery, pain relief or anaesthesia, providing a significant barrier to the strengthening of emergency and surgical care services and severely limiting their ability to respond to large-scale disaster and crisis situations.

The severe gaps in infrastructure and capital are also obstacles for the delivery of basic primary care in these facilities. Absence of key infrastructural elements such as water, electricity, and oxygen was common in the surveyed facilities. Lack of sterilisation tools and supplies for infection prevention was also a common feature. Establishing management guidelines for surgical infrastructure and targeting strategies to address the aforementioned lacks in infrastructure is a priority. This would not only increase the quality of surgical services, but also that of basic primary care services offered by these facilities.

Strengthening of surgical systems will reduce the disease burden of surgically related issues and increase progress towards achieving the 2015 Millennium Development Goals (MDGs). Strengthening surgical care delivery can help achieve MDGs 1 (eradication of poverty), ${ }^{18} 4$ (child health), 5 (maternal health) and 6 (HIV/AIDS prevention). ${ }^{22}$ Investing in oxygen and basic infrastructure, such as electricity and running water, will also serve to benefit patients suffering from a range of conditions.

To meet the needs of LMICs, the WHO EESC programme, with its partners worldwide, developed the Integrated Management for Emergency and Essential Surgical Care (IMEESC) toolkit (WHO IMEESC Toolkit: http:// www.who.int/surgery/en). This toolkit guides policies, research for evidence-based planning (WHO EESC Situation Analysis Tool to assess emergency, trauma, obstetrics, anaesthesia and surgical services, WHO EESC Global Database), training, best practice protocols monitoring and evaluation of the progress of surgical care systems. The IMEESC toolkit provides guidance for policy-makers, managers and providers at various levels of care. It also includes instructional videos, training modules on emergency and trauma for frontline health workers, disaster management resources and monitoring and evaluation.

This study provides insight into the surgical capacity of Somalia, using the WHO Tool for Situational Analysis to 
Assess EESC. Addressing the gaps identified in this study is needed not only to strengthen surgical care, but also holistic health systems in Somalia. ${ }^{25}$ Further research is needed to determine the burden of surgical disease in Somalia and to determine the cost-benefit of specific interventions to improve surgical services.

Acknowledgements The following members of GIEESC in Somalia were instrumental in obtaining the reported data: Dr Yassin Arab Abdi, Dr Nima Abdi Hassan, Dr Mohamed Samy Salama, Dr Mahmoud Mostafa El-Antably, Dr Jamal Mohamed Jama, Dr Abdulcadir Mohamud Giama, Dr Nura Mohamed Ahmed, Dr Saeed Hussien Legeh, Dr Risaaq Mohamoud Yousuf, Dr Cabdi Qaadu Bikri, Dr Ahmed Jama, Dr Muse Geele and Dr Noor M Noor.

Contributors NE and AS analysed and interpreted the data, drafted the article, revised it and finally approved the submitted version. MC contributed to the conception and design, acquisition and interpretation of the data, helped draft the article, made critical revisions and finally approved the submitted version. OS, ME, GP and Al contributed to acquisition of the data, made critical revisions and finally approved the submitted version.

Funding This research received no specific grant from any funding agency in the public, commercial or not-for-profit sectors.

Disclaimer The authors include staff members of WHO. They are responsible for the views expressed in this publication and do not necessarily represent the decisions or stated policy of WHO.

Competing interests None.

Provenance and peer review Not commissioned; externally peer reviewed.

Data sharing statement No additional data are available.

Open Access This is an Open Access article distributed in accordance with the Creative Commons Attribution Non Commercial (CC BY-NC 3.0) license, which permits others to distribute, remix, adapt, build upon this work noncommercially, and license their derivative works on different terms, provided the original work is properly cited and the use is non-commercial. See: http:// creativecommons.org/licenses/by-nc/3.0/

\section{REFERENCES}

1. Debas HT, Gosselin R, McCord C, et al. Surgery. In: Jamison D. ed. Disease control priorities in developing countries. 2nd edn. New York: Oxford University Press, 2006:1245-59.

2. Weiser TG, Regenbogen SE, Thompson KD, et al. An estimation of the global volume of surgery: a modelling strategy based on available data. Lancet 2008;372:139-44.

3. World Health Organisation. Regional office for the Eastern Mediterranean, Cairo. Country cooperation strategy for WHO and Somalia 2010-2014. 2010.

4. UNICEF. The private sector and health: a survey of Somaliland private pharmacies. 2008.

5. UNDP. Population projections. 2007
6. UNDP. Millennium Development Goals Report for Somalia. 2007.

7. Penoyar $\mathrm{T}$, Cohen $\mathrm{H}$, Kibatala $\mathrm{P}$, et al. Emergency and surgery services of primary hospitals in United Republic of Tanzania. BMJ Open 2012;2:e000369.

8. Natuzzi ES, Kushner A, Jagilly R, et al. Surgical care in the Solomon Islands: a road map for universal surgical care delivery. World $\mathrm{J}$ Surg 2011;35:1183-93.

9. Idriss A, Shivute N, Bickler S, et al. Emergency, anaesthetic and essential surgical capacity in the Gambia. Bull World Health Organ 2011;89:565-72.

10. Sherman L, Clement $\mathrm{P}$, Cherian $\mathrm{M}$, et al. Implementing Liberia's poverty reduction strategy: an assessment of emergency and essential surgical care. Arch Surg 2011;146:35-9.

11. Choo S, Perry H, Hesse AA, et al. Assessment of capacity for surgery, obstretrics and anaesthesia in 17 hospitals in Ghana using a WHO assessment tool. Trop Med Int Health 2010;15: 1109-15.

12. Contini S, Taqdeer A, Cherian M, et al. Emergency and essential surgical services in Afghanistan: still a missing challenge. World $\mathrm{J}$ Surg 2010;34:473-79.

13. Taira BR, Cherian MN, Yakandawala $\mathrm{H}$, et al. Survey of emergency and surgical capacity in the conflict-affected regions of Sri Lanka. World J Surg 2010;34:428-32.

14. Kingham TP, Kamara TB, Cherian MN, et al. Quantifying surgical capacity in Sierra Leone: a guide for improving surgical care. Arch Surg 2009;144:122-7.

15. Cherian MN, Noel L, Buyanjargal Y, et al. Essential emergency and surgical procedures in resource-limited facilities: a WHO workshop in Mongolia. World Hosp Health Serv 2004;40:24-9.

16. Farmer P, Kim J. Surgery and global health: a view from beyond the OR. World J Surg 2008;32:533-6.

17. Johnson WD. Surgery as a global health issue. Surg Neurol Int 2013;4:47

18. Funk LM, Weiser TG, Berry WR, et al. Global operating theatre distribution and pulse oximetry supply: an estimation from reported data. Lancet 2010;376:1055-61.

19. Smith-Rohrberg Maru D, McGee HM, Brady JS, et al. Global Surgical Care in 2030: Metrics and Strategies for Expansion in Access and Quality. 2013. http://www.worldwewant2015.org/file/ 298623/download/323967

20. Kushner Al, Cherian MN, Shokohmand AS, et al. Addressing the millennium development goals from a surgical perspective: essential surgery and anesthesia in 8 low- and middle-income countries. Arch Surg 2010;145:154-9.

21. United Nations. A new global partnership: eradicate poverty and transform economies through sustainable development: the report of the high-level panel of eminent persons on the post-2015 development agenda. United Nations Publication, 2013.

22. Jamison D, Jha P, Bloom D. Diseases-disease control. In: Lomborg B. ed. Global crises, global solutions. 2nd edn. New York: Cambridge University Press, 2009:129-63.

23. Ozgediz D, Jamison D, McQueen K. The burden of surgical conditions and access to surgical care in low- and middle-income countries. Bull World Health Organ 2008;86:646-7.

24. Cherian MN, Merry AF, Wilson IH. The World Health Organization and anaesthesia. Anaesthesia 2007;62:65-6.

25. Hedges JP, Mock CN, Cherian MN. The political economy of emergency and essential surgery in global health. World J Surg 2010;34:2003-6. 